\title{
Survival and consciousness recovery are better in the minimally conscious state than in the vegetative state
}

Frédéric Faugeras, Benjamin Rohaut, Mélanie Valente, Jacobo Sitt, Sophie Demeret, Francis Bolgert, Nicolas Weiss, Alexandra Grinea, Clémence Marois, Marion Quirins, Athena Demertzi, Federico Raimondo, Damien Galanaud, Marie-Odile Habert, Denis Engemann, Louis Puybasset \& Lionel Naccache

To cite this article: Frédéric Faugeras, Benjamin Rohaut, Mélanie Valente, Jacobo Sitt, Sophie Demeret, Francis Bolgert, Nicolas Weiss, Alexandra Grinea, Clémence Marois, Marion Quirins, Athena Demertzi, Federico Raimondo, Damien Galanaud, Marie-Odile Habert, Denis Engemann, Louis Puybasset \& Lionel Naccache (2018) Survival and consciousness recovery are better in the minimally conscious state than in the vegetative state, Brain Injury, 32:1, 72-77, DOI: 10.1080/02699052.2017.1364421

To link to this article: https://doi.org/10.1080/02699052.2017.1364421

Published online: 20 Nov 2017.

Submit your article to this journal $[\pi$

Llll Article views: 175

Q View related articles ¿

View Crossmark data $₫$ 


\title{
Survival and consciousness recovery are better in the minimally conscious state than in the vegetative state
}

\author{
Frédéric Faugeras ${ }^{\mathrm{a}, \mathrm{b}, c, \mathrm{~d}}$, Benjamin Rohaut ${ }^{\mathrm{a}, \mathrm{b}, \mathrm{c}, \mathrm{d}}$, Mélanie Valente ${ }^{\mathrm{c}, \mathrm{d}}$, Jacobo Sitt ${ }^{c, d}$, Sophie Demeret ${ }^{\mathrm{a}}$, Francis Bolgert ${ }^{\mathrm{a}}$, \\ Nicolas Weiss ${ }^{a}$, Alexandra Grinea ${ }^{a}$, Clémence Marois ${ }^{\mathrm{a}, c, d}$, Marion Quirins ${ }^{c, d}$, Athena Demertzi ${ }^{c, d}$, Federico Raimondo ${ }^{c, d}$, \\ Damien Galanaud (1) ${ }^{\mathrm{e}, \mathrm{f}}$, Marie-Odile Habert ${ }^{\mathrm{f}, \mathrm{g}, \mathrm{h}}$, Denis Engemannn ${ }^{\mathrm{c}, \mathrm{d}}$, Louis Puybasset ${ }^{\mathrm{f}, \mathrm{i}}$, and Lionel Naccache $\mathbb{1}^{\mathrm{a}, \mathrm{b}, \mathrm{b}, \mathrm{d}, \mathrm{d}, \mathrm{f}}$
}

${ }^{a} \mathrm{AP}-\mathrm{HP}$, Groupe hospitalier Pitié-Salpêtrière, Department of Neurology, Paris, France; ${ }^{\mathrm{b}} \mathrm{AP}-\mathrm{HP}$, Groupe hospitalier Pitié-Salpêtrière, Department of Neurophysiology, Paris, France; CINSERM, U 1127, Paris, France; dInstitut du Cerveau et de la Moelle épinière, ICM, PICNIC Lab, Paris, France; ${ }^{\text {AP-HP, }}$ Groupe hospitalier Pitié-Salpêtrière, Department of Neuroradiology, Paris, France; ${ }^{\prime}$ Sorbonne Universités, UPMC Univ Paris 06, Faculté de Médecine Pitié-Salpêtrière, Paris, France; ${ }^{\mathrm{A} A P-H P}$, Groupe hospitalier Pitié-Salpêtrière, Department of Nuclear Medicine, Paris, France; ${ }^{\text {h}}$ Sorbonne Universités, UPMC Univ Paris 06, CNRS, INSERM, Laboratoire d'Imagerie Biomédicale, Paris, France; 'AP-HP, Groupe hospitalier Pitié-Salpêtrière, Department of Anesthesiology, Paris, France

\begin{abstract}
Background: The prognosis value of early clinical diagnosis of consciousness impairment is documented by an extremely limited number of studies, whereas it may convey important information to guide medical decisions.

Objective: We aimed at determining if patients diagnosed at an early stage ( $<90$ days after brain injury) as being in the minimally conscious state (MCS) have a better prognosis than patients in the vegetative state/Unresponsive Wakefulness syndrome (VS/UWS), independent of care limitations or withdrawal decisions.

Methods: Patients hospitalized in ICUs of the Pitié-Salpêtrière Hospital (Paris, France) from November 2008 to January 2011 were included and evaluated behaviourally with standardized assessment and with the Coma Recovery Scale-Revised as being either in the VS/UWS or in the MCS. They were then prospectively followed until 1July 2011 to evaluate their outcome with the GOSE. We compared survival function and outcomes of these two groups.

Results: Both survival function and outcomes, including consciousness recovery, were significantly better in the MCS group. This difference of outcome still holds when considering only patients still alive at the end of the study.

Conclusions: Early accurate clinical diagnosis of VS/UWS or MCS conveys a strong prognostic value of survival and of consciousness recovery.
\end{abstract}

\section{ARTICLE HISTORY}

Received 20 November 2017 Revised 24 May 2017

Accepted 2 August 2017

\section{KEYWORDS}

Clinical; DOC patients; outcomes; prognosis

\section{Introduction}

Since the definition of the minimally conscious state (MCS) in 2002 (1), a large number of studies reported the differences that distinguish this state from the Vegetative State/Unresponsive Wakefulness Syndrome (VS/UWS) (2) in terms of behaviour, brain structure and brain activity (3). MCS corresponds to a state being closer to consciousness than VS/UWS, and it has been associated with a better prognosis than the VS/UWS. This prognostic value constitutes one of the major arguments used to emphasize the importance to distinguish these two clinical states early on (4). However, to date, only four studies documented this alleged better prognostic value. These reports include a retrospective study limited to patients admitted to a rehabilitation unit (5) and a prospective study that was conducted on 32 patients (12 in a VS/UWS and 20 in a MCS) (6) showing that among the nine patients who recovered consciousness during the 6 months following brain injury, eight were initially in the MCS. A third retrospective cohort study compared long-term outcomes of 12 patients in the VS/UWS and of 39 patients in the MCS (7), up to 5 years after injury. While none of the patients in the VS/UWS improved, 13 emerged from MCS to conscious state. Finally, a fourth prospective study considering 116 patients in the VS/UWS and 84 patients in the MCS, diagnosed at one month from injury than followed at 3, 6 and 12 months, was also in favour of a better prognosis in terms of survival and functional outcomes in the MCS than in the VS/UWS and within these categories in traumatic than non-traumatic etiologies (8). However, this last study remained purely descriptive and did not include hypothesis testing statistical analyses. Note also that positive outcome was defined as being in an MCS or exit-MCS (see below for definition) for patients initially in the VS/UWS and as being in an exit-MCS for patients initially in the MCS, without further detailing the precise functional status of the patients subsequently in the exit-MCS. In the present study, we prospectively and statistically compared prognosis at least 6 months from injury in terms of both survival and functional outcome, in a large set of patients in the VS/UWS and the MCS included at the early stage of their injury.

CONTACT Frédéric Faugeras faugerasfrederic@gmail.com 0 CRICM-INSERM/UPMC UMRS 975 CHU Pitiè-Salpêtrière 47 Bd de I'Hôpital Bâtiment ICM 4ème ètage - Pièce 4.002975651 PARIS cedex 13.

Colour versions of one or more of the figures in the article can be found online at www.tandfonline.com/ibij.

(c) 2017 Taylor \& Francis Group, LLC 
To reduce the potential impact of self-fulfilling prophecy bias, which may account for part of the patients who deceased following a decision of care limitations based on clinical presentation (i.e., more care limitations for patients in the VS/UWS than for patients in the MCS), we also performed a dedicated analysis on patients still alive at the end of the study.

\section{Glossary}

AA: Arterial Aneurysm, ADEM: Acute disseminated encephalomyelitis, AVM: Arteriovenous Malformation, CRS-R: Coma Recovery Scale-Revised, EEG: Electroencephalography, F: Female, fMRI: functional Magnetic Resonance Imaging, GOSE: Glasgow Outcome Scale Extended, ICH: Intracranial Haemorrhage, ICUs: Intensive Care Units, M: Male, MCS: Minimally Conscious State, TBI: Traumatic Brain Injury, VS/ UWS: Vegetative State/Unresponsive Wakefulness Syndrome.

\section{Methods}

This study has been approved by the Ethical Committee of the Pitié-Salpêtrière Hospital (Paris, France) and was carried in accordance with French Law on biomedical research which does not require a consent form for research protocols corresponding to 'regular care' ('Soins courants'). As required by the French Law, relatives of patients unable to communicate were informed about the use of their data and did not oppose to this project.

\section{Patients}

Patients were hospitalized in Intensive Care Units (ICUs), and our team (FF, BR, LN) was solicited for an expert evaluation of consciousness.

\section{Inclusion criteria were}

- Patients were diagnosed as being in VS/UWS or MCS after the neurobehavioural assessment (see below).

- The delay between the date of injury and initial consciousness assessment was less than three months (90 days), in order to include patients at a stage associated with a higher probability of clinical evolution. This points in particular to the patients in a VS/UWS from anoxic etiology (9).

- The delay between the inaugural injury and outcome assessment was greater or equal to six months given the low probability of further recovery beyond these delays (9).

- The end of the study was fixed at 1 July 2011.

- Patients were clinically assessed without any sedation within at least 24 hours.

\section{Neurobehavioural assessment}

Patients were assessed by a careful neurological examination and by the use of the French version of the Coma Recovery ScaleRevised (CRS-R) (1,10). This scale consists of 23 items that comprise six subscales addressing auditory, visual, motor, oromotor, communication and arousal functions. CRS-R subscales are made up of hierarchically arranged items from no response to reflexive than cognitively mediated response. This scoring enables a distinction to be drawn between minimally conscious (MCS) and vegetative state (VS/UWS). Furthermore, when patients can functionally use two different objects placed in their hand (comb and cup for example) or respond to six simple questions delivered through visual or auditory modalities (six questions per modality) by a yes/no verbal response or by a code of communication, subjects are defined as patients in the exitMCS or conscious. Only one evaluation was performed for each subject by one member of our expert team (FF, BR, LN).

Note that CRS-R has been shown to be more sensitive than the Glasgow Coma Scale (11), the FOUR score (12) and the WHIM scale (13) to differentiate patients in the MCS from patients in the VS/UWS (10).

\section{Evaluation of variables of interest}

For the survival analysis, the time-to-event corresponded to the delay (in days) between initial injury and death. Patients still alive at the end of the study were considered as right censored.

For the prognosis analysis, the outcome of patients who survived after hospitalization was evaluated by the Glasgow Outcome Scale-Extended (GOSE) through a phone interview with a close relative or the physicians of the patients (14). We used a cut-off value of 4 in order to define a good outcome (GOSE score $\geq 4$ ). A GOSE score superior or equal to 4 corresponds to a: 'patient with severe disability but conscious who can be left at least 8 hours during the day without assistance' (15). Inversely, GOSE scores inferior to 4 include both patients in the VS/UWS and the MCS. Our phone interview followed the GOSE interview and included items of the CRS-R in order to try to disentangle VS/UWS from MCS and to detect patients in the exit-MCS. By this way, we made sure that GOSE scores $\geq$ 4 corresponded to patients who were conscious and that no patients who were conscious were assigned a GOSE score of 3 .

\section{Data analysis}

The survival function was computed for each group of interest (patients in the VS/UWS and in the MCS). A log-rank test was used to assess statistical difference between the survival function of these two groups.

The GOSE scores at the end of our study were separated in GOSE $<4$ versus GOSE $\geq 4$ and compared with a $\chi 2$ test (when taking into account all the population) or Fisher exact test (when $\chi^{2}$ test was not applicable that is when taking into account only patients still alive at the end of the study) for patients in the VS/UWS and in the MCS separately.

We controlled for the very few variables classically associated with prognosis in this population of patients, which are: etiology, age, delay from injury and delay of clinical course (9). To this end, two-tailed unpaired Student t-tests were used for continuous variables (age, delays) and $\chi 2$ tests for discrete variables such as etiologies. All statistical tests were performed with $\mathrm{R}$ survival package (R Core Team (2012); https://cran.r-project.org/web/ packages/survival/survival.pdf) and in Matlab (R2009b).

\section{Results}

All of the consecutive 67 patients responding to our inclusion criteria were clinically assessed from November 2008 to 
Table 1. Description of patients.

\begin{tabular}{|c|c|c|c|c|c|c|c|c|}
\hline Patient & Age & Sex & Etiology & $\begin{array}{l}\text { Delay for } \\
\text { Clinical } \\
\text { Appraisal }\end{array}$ & $\begin{array}{c}\text { CRS-R } \\
\text { (total and subscores) }\end{array}$ & Survival Time & Right Censored & Outcome (GOSE) \\
\hline VS/UWS1 & 24 & $M$ & Intoxication & 20 & $4(1 / 0 / 0 / 1 / 0 / 2)$ & 730 & Yes & 5 \\
\hline VS/UWS2 & 73 & $\mathrm{~F}$ & Ischemic infarction & 62 & $7(1 / 1 / 2 / 2 / 0 / 1)$ & 93 & No & 1 \\
\hline VS/UWS3 & 64 & M & $\begin{array}{l}\text { Multivisceral } \\
\text { failure }\end{array}$ & 50 & $6(2 / 1 / 1 / 1 / 0 / 1)$ & 58 & No & 1 \\
\hline VS/UWS4 & 31 & $M$ & Anoxia & 8 & $3(0 / 0 / 2 / 0 / 0 / 1)$ & 185 & No & 1 \\
\hline VS/UWS5 & 58 & $M$ & $\mathrm{ICH}$ & 38 & $6(1 / 1 / 2 / 1 / 0 / 1)$ & 98 & No & 1 \\
\hline VS/UWS6 & 65 & $M$ & Ischemic infarction & 56 & $3(0 / 0 / 1 / 1 / 0 / 1)$ & 92 & No & 1 \\
\hline VS/UWS7 & 38 & $M$ & $\mathrm{TBI}$ & 38 & $6(1 / 1 / 2 / 1 / 0 / 1)$ & 46 & No & 1 \\
\hline VS/UWS8 & 37 & $\mathrm{~F}$ & $\begin{array}{l}\text { Cerebral } \\
\text { toxoplasmosis }\end{array}$ & 29 & $5(1 / 1 / 2 / 1 / 0 / 1)$ & 31 & No & 1 \\
\hline VS/UWS9 & 69 & $\mathrm{~F}$ & $\mathrm{TBI}$ & 24 & $3(0 / 0 / 1 / 0 / 0 / 2)$ & 30 & No & 1 \\
\hline VS/UWS10 & 65 & $\mathrm{~F}$ & Anoxia & 31 & $4(1 / 1 / 0 / 1 / 0 / 1)$ & 40 & No & 1 \\
\hline VS/UWS11 & 37 & $M$ & Anoxia & 55 & $7(2 / 1 / 1 / 1 / 0 / 2)$ & 226 & Yes & 2 \\
\hline VS/UWS12 & 17 & $M$ & Anoxia & 10 & $2(0 / 0 / 1 / 0 / 0 / 1)$ & 24 & No & 1 \\
\hline VS/UWS13 & 61 & $\mathrm{~F}$ & ADEM & 25 & $1(0 / 0 / 0 / 0 / 0 / 1)$ & 748 & Yes & 3 \\
\hline VS/UWS14 & 47 & $\mathrm{~F}$ & Anoxia & 54 & $3(1 / 0 / 1 / 0 / 0 / 1)$ & 55 & No & 1 \\
\hline VS/UWS15 & 48 & $\mathrm{~F}$ & Anoxia & 14 & $3(0 / 0 / 1 / 1 / 0 / 1)$ & 21 & No & 1 \\
\hline VS/UWS16 & 61 & $M$ & $\mathrm{ICH}$ & 25 & $3(0 / 0 / 0 / 1 / 0 / 2)$ & 27 & No & 1 \\
\hline VS/UWS17 & 29 & $\mathrm{~F}$ & Anoxia & 86 & $4(1 / 0 / 1 / 1 / 0 / 1)$ & 105 & No & 1 \\
\hline VS/UWS18 & 65 & $\mathrm{~F}$ & Anoxia & 20 & $4(1 / 0 / 1 / 1 / 0 / 1)$ & 528 & No & 1 \\
\hline VS/UWS19 & 44 & $M$ & $\mathrm{ICH}$ & 42 & $5(1 / 0 / 1 / 1 / 0 / 2)$ & 736 & Yes & 3 \\
\hline VS/UWS20 & 67 & $M$ & $\mathrm{ICH} / \mathrm{AVM}$ & 25 & $5(1 / 0 / 1 / 1 / 0 / 2)$ & 31 & No & 1 \\
\hline VS/UWS21 & 46 & $M$ & Ischemic infarction & 89 & $5(1 / 0 / 1 / 1 / 0 / 2)$ & 185 & No & 1 \\
\hline VS/UWS22 & 70 & $\mathrm{~F}$ & $\mathrm{ICH} / \mathrm{AA}$ & 17 & $6(1 / 1 / 2 / 1 / 0 / 1)$ & 23 & No & 1 \\
\hline VS/UWS23 & 45 & $M$ & Anoxia & 19 & $7(2 / 1 / 1 / 1 / 0 / 2)$ & 32 & No & 1 \\
\hline VS/UWS24 & 63 & $M$ & Hypoglycaemia & 25 & $6(1 / 0 / 2 / 1 / 0 / 2)$ & 36 & No & 1 \\
\hline VS/UWS25 & 41 & $\mathrm{~F}$ & Anoxia & 7 & $4(0 / 0 / 2 / 1 / 0 / 1)$ & 10 & No & 1 \\
\hline VS/UWS26 & 47 & $M$ & Anoxia & 11 & $3(0 / 0 / 1 / 1 / 0 / 1)$ & 19 & No & 1 \\
\hline VS/UWS27 & 38 & $\mathrm{~F}$ & $\mathrm{ICH} / \mathrm{AA}$ & 30 & $7(1 / 1 / 2 / 1 / 0 / 2)$ & 33 & No & 1 \\
\hline VS/UWS28 & 33 & $M$ & $\mathrm{TBI}$ & 45 & $3(1 / 0 / 0 / 1 / 0 / 1)$ & 49 & No & 1 \\
\hline VS/UWS29 & 80 & $M$ & $\begin{array}{l}\text { Ischemic } \\
\text { infarction }\end{array}$ & 35 & $6(1 / 1 / 2 / 1 / 0 / 1)$ & 116 & No & 1 \\
\hline VS/UWS30 & 73 & $M$ & Anoxia & 9 & $4(0 / 0 / 2 / 1 / 0 / 1)$ & 14 & No & 1 \\
\hline VS/UWS31 & 71 & M & Anoxia & 17 & $4(1 / 0 / 1 / 1 / 0 / 1)$ & 72 & No & 1 \\
\hline VS/UWS32 & 37 & $\mathrm{~F}$ & $\mathrm{ICH}$ & 62 & $5(1 / 1 / 1 / 1 / 0 / 1)$ & 274 & Yes & 3 \\
\hline VS/UWS33 & 62 & $M$ & Anoxia & 10 & $7(2 / 1 / 1 / 2 / 0 / 1)$ & 12 & No & 1 \\
\hline MCS1 & 21 & $M$ & $\mathrm{ICH}$ & 22 & $8(1 / 3 / 1 / 1 / 0 / 2)$ & 431 & Yes & 4 \\
\hline MCS2 & 21 & $\mathrm{~F}$ & TBI & 24 & $8(3 / 1 / 2 / 1 / 0 / 1)$ & 495 & Yes & 4 \\
\hline MCS3 & 20 & $M$ & $\mathrm{TBI}$ & 39 & $17(3 / 4 / 5 / 2 / 1 / 2)$ & 364 & Yes & 3 \\
\hline MCS4 & 51 & $\mathrm{~F}$ & Hypoglycaemia & 14 & $8(1 / 3 / 2 / 1 / 0 / 1)$ & 372 & No & 1 \\
\hline MCS5 & 56 & $\mathrm{~F}$ & Anoxia & 10 & $15(3 / 3 / 5 / 2 / 1 / 1)$ & 244 & Yes & 4 \\
\hline MCS6 & 59 & $M$ & $\begin{array}{l}\text { Multivisceral } \\
\text { failure }\end{array}$ & 25 & $7(3 / 1 / 1 / 1 / 0 / 1)$ & 264 & Yes & 3 \\
\hline MCS7 & 22 & $M$ & $\mathrm{TBI}$ & 20 & $8(1 / 3 / 2 / 1 / 0 / 1)$ & 545 & Yes & 6 \\
\hline MCS8 & 50 & M & Anoxia & 6 & $8(3 / 1 / 1 / 1 / 0 / 2)$ & 854 & Yes & 5 \\
\hline MCS9 & 21 & $\mathrm{~F}$ & $\mathrm{TBI}$ & 16 & $13(3 / 3 / 5 / 1 / 0 / 1)$ & 543 & Yes & 6 \\
\hline MCS10 & 20 & $M$ & $\mathrm{TBI}$ & 25 & $11(3 / 3 / 2 / 1 / 0 / 2)$ & 542 & Yes & 6 \\
\hline MCS11 & 62 & $M$ & Meningitis & 23 & $7(0 / 3 / 2 / 1 / 0 / 1)$ & 32 & No & 1 \\
\hline MCS12 & 21 & $\mathrm{~F}$ & $\mathrm{TBI}$ & 29 & $8(1 / 3 / 1 / 1 / 0 / 2)$ & 525 & Yes & 4 \\
\hline MCS13 & 39 & $M$ & $\mathrm{ICH}$ & 26 & $10(3 / 3 / 1 / 1 / 0 / 2)$ & 28 & No & 1 \\
\hline MCS14 & 16 & $M$ & $\mathrm{TBI}$ & 30 & $12(3 / 3 / 4 / 1 / 0 / 1)$ & 659 & Yes & 4 \\
\hline MCS15 & 69 & $M$ & Anoxia & 9 & $13(3 / 3 / 4 / 2 / 0 / 1)$ & 35 & No & 1 \\
\hline MCS16 & 38 & $\mathrm{~F}$ & Anoxia & 17 & $15(3 / 3 / 5 / 2 / 1 / 1)$ & 529 & Yes & 6 \\
\hline MCS17 & 44 & $\mathrm{~F}$ & $\mathrm{ICH}$ & 8 & $17(4 / 5 / 5 / 1 / 1 / 1)$ & 587 & Yes & 5 \\
\hline MCS18 & 29 & $\mathrm{~F}$ & Anoxia & 83 & $15(3 / 3 / 5 / 2 / 0 / 2)$ & 185 & No & 1 \\
\hline MCS19 & 21 & $\mathrm{~F}$ & Hypoglycaemia & 22 & $18(3 / 4 / 5 / 2 / 1 / 3)$ & 885 & Yes & 6 \\
\hline MCS20 & 52 & $\mathrm{~F}$ & Anoxia & 34 & $19(4 / 5 / 5 / 2 / 1 / 2)$ & 452 & No & 1 \\
\hline MCS21 & 67 & $M$ & Stroke & 11 & $8(2 / 3 / 2 / 0 / 0 / 1)$ & 50 & No & 1 \\
\hline MCS22 & 51 & M & TBI & 25 & $11(2 / 2 / 3 / 1 / 1 / 2)$ & 502 & Yes & 6 \\
\hline MCS23 & 53 & $\mathrm{~F}$ & $\mathrm{ICH}$ & 47 & $18(3 / 4 / 5 / 3 / 1 / 2)$ & 536 & Yes & 3 \\
\hline MCS24 & 69 & $M$ & $\mathrm{ICH}$ & 25 & $9(3 / 1 / 2 / 1 / 1 / 1)$ & 40 & No & 1 \\
\hline MCS25 & 42 & M & $\mathrm{TBI}$ & 28 & $9(1 / 3 / 2 / 1 / 0 / 2)$ & 492 & Yes & 5 \\
\hline MCS26 & 59 & M & $\mathrm{TBI}$ & 24 & $9(3 / 1 / 1 / 2 / 0 / 2)$ & 485 & Yes & 4 \\
\hline MCS27 & 56 & $M$ & Status epilepticus & 30 & $8(3 / 3 / 0 / 1 / 0 / 1)$ & 47 & No & 1 \\
\hline MCS28 & 45 & M & TBI & 20 & $6(0 / 0 / 4 / 1 / 0 / 1)$ & 163 & No & 1 \\
\hline MCS29 & 54 & $\mathrm{M}$ & $\mathrm{ICH}$ & 21 & $10(2 / 3 / 2 / 1 / 0 / 2)$ & 35 & No & 1 \\
\hline MCS30 & 78 & $\mathrm{~F}$ & Meningitis & 27 & $7(1 / 1 / 3 / 1 / 0 / 1)$ & 44 & No & 1 \\
\hline MCS31 & 38 & $M$ & Anoxia & 27 & $12(2 / 3 / 4 / 1 / 0 / 2)$ & 107 & No & 1 \\
\hline MCS32 & 45 & $M$ & Stroke & 27 & $16(3 / 3 / 5 / 2 / 1 / 2)$ & 286 & Yes & 3 \\
\hline MCS33 & 43 & $\mathrm{~F}$ & TBI & 27 & $9(1 / 3 / 2 / 1 / 0 / 2)$ & 196 & Yes & 6 \\
\hline MCS34 & 42 & $\mathrm{~F}$ & $\mathrm{ICH} / \mathrm{AA}$ & 46 & $6(3 / 0 / 1 / 1 / 0 / 1)$ & 53 & No & 1 \\
\hline
\end{tabular}

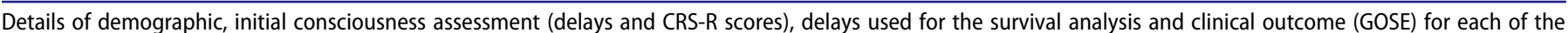
67 patients. 
January 2011, with date of injury ranging from 3 September 2008 to 7 December 2010 (see Table 1). Thirty-three patients were diagnosed as VS/UWS and 34 as MCS. Mean delay elapsed between initial injury and clinical evaluation was similar in the two groups: $33( \pm 22)$ days for the group of patients in the VS/UWS versus $26(+/-14)$ days for the group of patients in the MCS ( $\mathrm{t}$-value $=1.64 ; \mathrm{p}=0.11$ ). Similarly, mean delays between clinical evaluation and outcome assessment did not differ across the two groups of patients: 495 (+/-202) days for the group of patients in the VS/UWS versus $499(+/-184)$ days for the group of patients in the MCS ( $\mathrm{t}$-value $=0.08 ; \mathrm{p}=0.94$ ).

Patients in the MCS were slightly younger (mean $=43.4$ $(+/-17)$ years) than patients in the VS/UWS (mean $=51.7$ $(+/-17)$ years $)(t$-value $=2.02, \mathrm{p}=0.05)$. The sex-ratios $(\mathrm{M} / \mathrm{F})$ were respectively 1.54 and 1.43 for the group of patients in the VS/UWS and the group of patients in the MCS. Etiologies (TBI, anoxia, other) were not distributed similarly across the two groups $\left(\chi^{2}=9.59\right.$; d.o.f. $\left.=2 ; \mathrm{p}=0.008\right)$. Restricted analyses showed that these differences were driven by a larger proportion of TBI in the group of patients in the MCS (12 patients) than in the group of patients in the VS/UWS (2 patients; $\chi^{2}=8.66$; d.o.f. $\left.=1 ; \mathrm{p}=0.003\right)$. More patients having suffered from anoxia were also observed in the group of patients in the VS/UWS (14 patients) than in the group of patients in the MCS (7 patients; $\chi 2=3.71$; d.o.f. $=1 ; \mathrm{p}=0.05$ ).

The survival function was significantly better in the group of patients in the MCS than in the group of patients in VS/UWS (see Figure 1) (log-rank test, $\left.\chi^{2}=18.2, \mathrm{p}<10-4\right)$. Twenty eight patients in the VS/UWS (84.8\%) and 14 patients in the MCS $(41.2 \%)$ died during the study $(\chi 2=11.9, \mathrm{p}=0.0006)$. Mean delay of death was respectively $74(+/-101)$ and $117(+/-135)$ days for the group of patients in the VS/UWS and in the MCS ( $t$ value $=-1.18, \mathrm{p}=0.25)$. The median survival time was equal to 46 days in the group of patients in the VS/UWS and superior to 368 days in the group of patients in the MCS. As mentioned

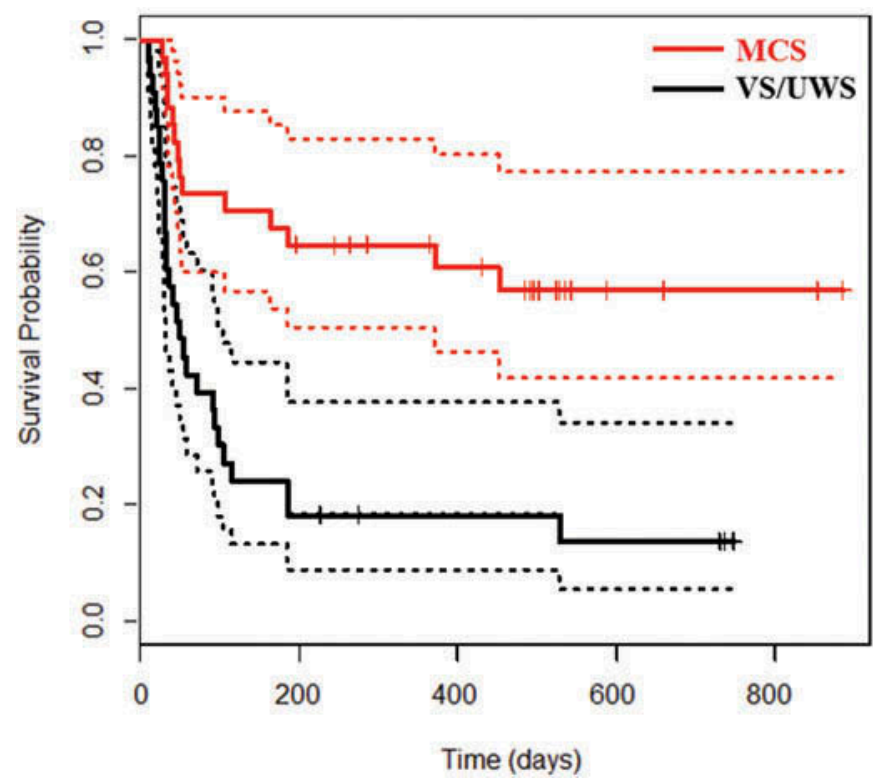

Figure 1. Survival in patients in the VS/UWS and in the MCS.

Kaplan-Meier survival curves with their $95 \%$ confident intervals for patients in the VS/UWS (in red) and in the MCS (in black). above, TBI etiology was significantly more frequent in patients in the MCS than in the VS/UWS, and patients in the MCS were significantly younger than patients in the VS/UWS. Given that TBI etiology and young age are generally associated with a better prognosis (6), we ran a Cox model by considering outcome (alive/ dead) as a dependent variable and age, etiology and clinical status as predictors. We found an effect of clinical status $(\mathrm{OR}=0.44$ [0.22-0.88]; $\mathrm{p}=0.02)$ and age $(\mathrm{OR}=1.02[1.00-1.05] ; \mathrm{p}=0.02)$ but not of etiology $(\mathrm{OR}=0.41$ [0.11-1.47]; $\mathrm{p}=0.17)$.

Outcomes at the end of the study (GOSE scores $<4$ versus GOSE scores $\geq 4$ which correspond to patients in a conscious state) were also better for patients in the MCS than for patients in the VS/UWS (Figure2): $47 \%$ of patients in the MCS had a good outcome in comparison with only $3 \%$ of patients in the VS/UWS ( $\chi 2=14.9, \mathrm{p}=0.0001)$. To identify factors associated with a good outcome, we then ran a logistic regression analysis with GOSE $(<4 / \geq 4)$ as a dependent variable and age, etiology and clinical status (VS/UWS vs MCS) as predictors. We found an effect of clinical status $(\mathrm{OR}=22.7$ [3.3-474.2]; $\mathrm{p}=0.007)$, age $(\mathrm{OR}=0.93$ [0.87-0.98]; $\mathrm{p}=0.02)$ and a trend for a better prognosis in patients having suffered from TBI $(\mathrm{OR}=1.564 .8$ [0.9-30.4]; $\mathrm{p}=0.08)$.

Finally, we aimed at reducing a possible self-fulfilling prophecy bias driven by the initial diagnostic label and its possible impact on care-withdrawal or care-limitation decisions. To do so, we compared outcomes of patients who were still alive at the end of the study (5 patients in the VS/UWS and 20 patients in the MCS; follow-up duration ranged from 196 to 886 days; mean follow-up duration $=508(+/-193)$ days; median follow-up duration $=527$ days) .

Crucially, patients initially diagnosed as being in a VS/UWS and who were still alive by the end of the study also had a significant poorer outcome than patients initially diagnosed as being in the MCS $\left(\chi^{2}=4.1, \mathrm{p}=0.04\right.$, Fischer exact test, $\left.\mathrm{p}=0.02\right)$.

\section{Discussion}

In a population of 67 patients suffering from a disorder of consciousness, and who were either in the VS/UWS or in the MCS, we showed that the initial diagnosis of consciousness impairment in ICUs conveys a strong prognostic value. This result probably captures an important determinant of prognosis because it holds in spite of the single consciousness assessment (covering a $\sim 1$ hour time-window of examination) performed in these patients at the early stage frequently associated with fast fluctuations of consciousness level. To the best of our knowledge, this result obtained in a prospective study was conducted on the largest sample of patients at the acute stage so far reported in the literature and confirms previous studies. It further strengthens the importance of an early and rigorous distinction of VS/UWS and MCS in terms of prognostic information. One limitation of our study is the single detailed neurobehavioural assessment at the inclusion stage. Given the notable fluctuations observed in these patients, one may wonder if we would not have underestimated some patients in the MCS as being in the VS/UWS. Note however that such a misclassification would have played against our findings. Therefore, by observing significant differences in terms of outcomes between patients in the MCS and the VS/UWS, we were able to emphasize the importance of initial neurobehavioural state. 

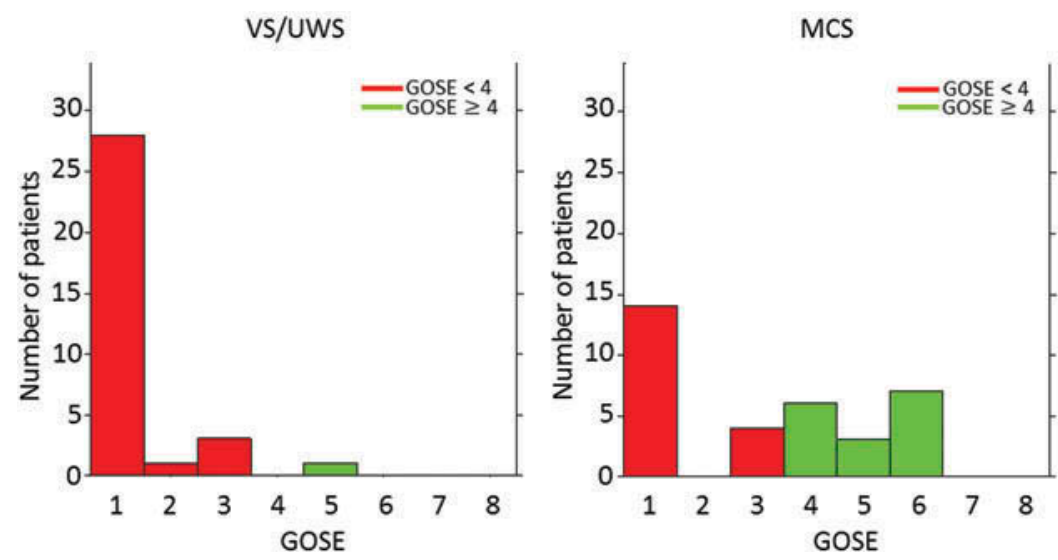

Figure 2. Consciousness recovery in patients in the VS/UWS and in the MCS. Histograms of VS/UWS and MCS outcomes evaluated with the GOSE scale.

Another limitation of our study could be the maximal delay of inclusion (3 months) and the minimal delay of functional evaluation with the GOSE (6 months) in particular in the traumatic population in whom clinical progression is possible up to one year post injury. Nevertheless, note that an inclusion delay larger than 3 months is difficult to achieve in the ICUs. As regards the delay of functional evaluation, none of the patients in the VS/UWS from traumatic or nontraumatic etiologies still alive at the end of the study were followed less than one year and three months respectively (see Table).

Most patients in the VS/UWS died during the study $(28 / 33=84.8 \%)$, whereas approximately half of patients in the MCS were still alive by the end of the study (20/ $34=58.8 \%)$. The survival difference reported in this study was even more pronounced in terms of prognosis by considering patients with GOSE $\geq 4$ versus patients with GOSE $<4$. These two results cannot simply be explained by a self-fulfilling prophecy effect given that this difference of outcome persisted even when restricting the analysis to patients still alive by the end of the study. In the nearer future, the combination of clinical evaluation with complementary measures stemming from brain structure $(16,17)$, brain metabolism (18) and brain activity with bedside EEG $(19,20)$ and fMRI $(3,21)$ may further increase the accuracy of prognosis prediction. From an ethical point of view, we think that the ability to enrich objective knowledge of the patient's current cognitive status as well as his/her prognosis of consciousness recovery improves the highly complex care decision making for these patients. This objective knowledge stems from behavioural but also from structural and functional brain imaging tools. Obviously, many variables have to be taken into account, including patient's personal point of view when available (e.g., advance directives) (22). By showing, in the present work, the value of initial conscious status (MCS vs VS/ UWS), we confirm the importance of clinical and behavioural examination to inform patient-related decision making.

\section{Declaration of interest}

The authors report no declarations of interest.

\section{Funding}

This work has been supported by the Fondation pour la Recherche Médicale ('Equipe FRM 2015' grant, by the programme 'Investissements d'avenir' ANR-10-IAIHU-06, by the 'ANR-CogniComa', by the ANR 14-CE15-001304 , by the 'Recovery of consciousness after severe brain injury Phase II' grant of the James S. McDonnell Foundation, and the "Grand Prix Lamonica de Neurologie" (Académie des Sciences to LN).

\section{ORCID}

Damien Galanaud (D) http://orcid.org/0000-0002-9285-8121

Lionel Naccache (D) http://orcid.org/0000-0002-2874-1009

\section{References}

1. Giacino JT, Ashwal S, Childs N, Cranford R, Jennett B, Katz DI, Kelly JP, Rosenberg JH, Whyte J, Zafonte RD, et al. The minimally conscious state: definition and diagnostic criteria. Neurology. 2002;58:349-53. doi:10.1212/WNL.58.3.349.

2. Laureys S, Celesia GG, Cohadon F, Lavrijsen J, Leon-Carrion J, Sannita WG, Sazbon L, Schmutzhard E, Von Wild KR, Zeman A, et al. Unresponsive wakefulness syndrome: a new name for the vegetative state or apallic syndrome. BMC Med. 2010; 8:68.

3. Laureys S, Owen AM, Schiff ND. Brain function in coma, vegetative state, and related disorders. Lancet Neurol. 2004;3(9):537-46.

4. Gosseries O, Zasler ND, Laureys S. Recent advances in disorders of consciousness: focus on the diagnosis. Brain Injury. 2014;28 (9):1141-50.

5. Klein AM, Howell K, Vogler J, Grill E, Straube A, Bender A. Rehabilitation outcome of unconscious traumatic brain injury patients. J Neurotrauma. 2013;30(17):1476-83.

6. Noe E, Olaya J, Navarro MD, Noguera P, Colomer C, GarciaPanach J, Rivero S, Moliner B, Ferri J. Behavioral recovery in disorders of consciousness: a prospective study with the Spanish version of the Coma Recovery Scale-Revised. Arch Phys Med Rehabil. 2012;93(3):428-33, e12.

7. Luaute J, Maucort-Boulch D, Tell L, Quelard F, Sarraf T, Iwaz J, Boisson D, Fischer C. Long-term outcomes of chronic minimally conscious and vegetative states. Neurology. 2010;75(3):246-52.

8. Bruno MA, Ledoux D, Vanhaudenhuyse A, Gosseries O, Thibault A, Laureys S. Prognosis of patients with altered state of consciousness. In: Schnakers C, Laureys S, Editors. Coma and disorders of consciousness. London: Springer-Verlag; 2012.

9. The Multi-Society Task Force on PVS. Medical aspects of the persistent vegetative state (2). N Engl J Med. 1994;330:1572-79.

10. Schnakers C, Majerus S, Giacino J, Vanhaudenhuyse A, Bruno M-A, Boly M, Moonen G, Damas P, Lambermont B, Lamy M, et al. A 
French validation study of the Coma Recovery Scale-Revised (CRSR). Brain Injury. 2008;22:786-92. doi:10.1080/02699050802403557.

11. Teasdale G, Jennett B. Assessment of coma and impaired consciousness. A practical scale. The Lancet. 1974;304(7872):81-84. doi:10.1016/S0140-6736(74)91639-0.

12. Wijdicks EFM, Bamlet WR, Maramattom BV, Manno EM, McClelland RL. Validation of a new coma scale: the FOUR score. Ann Neurol. 2005;58(4):585-93. doi:10.1002/(ISSN)15318249.

13. Shiel A, Horn SA, Wilson BA, Watson MJ, Campbell MJ, McLellan DL. The Wessex Head Injury Matrix (WHIM) main scale: a preliminary report on a scale to assess and monitor patient recovery after severe head injury. Clin Rehabil. 2000;14(4):408-16. doi:10.1191/0269215500cr326oa.

14. Wilson JT, Pettigrew L.E, Teasdale GM. Structured interviews for the Glasgow outcome scale and the extended Glasgow outcome scale: Guidelines for their use. J Neurotrauma. 1998;15(8):573-85. doi:10.1089/neu.1998.15.573.

15. Lu J, Marmarou A, Lapane K, Turf E, Wilson L. A method for reducing misclassification in the extended Glasgow outcome score. J Neurotrauma. 2010;27(5):843-52. doi:10.1089/ neu.2010.1293.

16. Galanaud D, Perlbarg V, Gupta R, Stevens RD, Sanchez P, Tollard E, De Champfleur NM, Dinkel J, Faivre S, Soto-Ares G, et al. Assessment of white matter injury and outcome in severe brain trauma: a prospective multicenter cohort. Anesthesiology. 2012;117(6):1300-10. doi:10.1097/ALN.0b013e3182755558.
17. Luyt C-E, Galanaud D, Perlbarg V, Vanhaudenhuyse A, Stevens RD, Gupta R, Besancenot H, Krainik A, Audibert G, Combes A, et al. Diffusion tensor imaging to predict long-term outcome after cardiac arrest: a bicentric pilot study. Anesthesiology. 2012;117 (6):1311-21. doi:10.1097/ALN.0b013e318275148c.

18. Stender J, Gosseries O, Bruno M-A, Charland-Verville V, Vanhaudenhuyse A, Demertzi A, Chatelle C, Thonnard M, Thibaut A, Heine L, et al. Diagnostic precision of PET imaging and functional MRI in disorders of consciousness: a clinical validation study. The Lancet. 2014;384(9942):514-22. doi:10.1016/ S0140-6736(14)60042-8.

19. Sitt J, King JR, El Karoui I, Rohaut B, Faugeras F, Gramfort A, Cohen L, Sigman M, Dehaene S, Naccache L. Large scale screening of the neural signatures of consciousness in vegetative and minimally conscious state patients. Brain:J Neurol. 2014; 137(Pt 8):2258-70.

20. Wang F, Di H, Hu X, Jing S, Thibaut A, Di Perri C, Huang W, Nie Y, Schnakers C, Laureys S. Cerebral response to subject's own name showed high prognostic value in traumatic vegetative state. BMC Medicine. 2015;13:83.

21. Demertzi A, Antonopoulos G, Heine L, Voss HU, Crone JS, De Los Angeles C, Bahri MA, Di Perri C, Vanhaudenhuyse A, Charland-Verville $\mathrm{V}$, et al. Intrinsic functional connectivity differentiates minimally conscious from unresponsive patients. Brain:J Neurol. 2015;138(Pt 9):2619-31.

22. Bernat JL. Chronic disorders of consciousness. Lancet. 2006;367:1181-92. 